Review paper

UDK: 681.625.3:62-7

\title{
Integrated maintenance management model in the printing industry
}

\author{
Author: Csaba Horváth ${ }^{1}$ \\ ${ }^{1}$ Óbuda University, Institute of Media Technology, Budapest/ Nyomdatechnika Kft., Debrecen, Hungary
}

\begin{abstract}
Rapid technological and economic changes are setting radically new task for maintenance divisions of printing works. In this dissertation the author provides a summary on the possible approaches for the adoption to the new requirements. He formulates his situation analysis based on an exhaustive questionnaire survey, and points out the currents of changes and challenges caused by the expected developments in the maintenance field of the printing industry.

Based on the possible answers on these challenges, the Author has compiled a - yet missing - maintenance management model that encompasses the maintenance specialties of the industry, as well as the professional heritage and the latest scientific accomplishments in the discipline of maintenance.

The model is based on the widely accepted quality focused maintenance approach, that is supplemented by the Author with four new aspects - 1) reliability-focused culture, 2) quality management system, 3) employment of external service provides, 4) maintenance characteristics specific to printing machinery - determining their effects and integrating them into one single system.

In order to construct the model, the Author develops specific solutions that can be seen as own scientific achievements on the specification of maintenance characteristics of printing machinery; on the efficiency improving applications of quality management systems, modern knowledge management and reliability focused corporate culture; and on the implementation of a maintenance information system.
\end{abstract}

Keywords: maintenance of printing plants, maintenance models, corporate culture, reliability

"God grant me the serenity to accept the things I cannot change, courage to change the things I can, and wisdom to always tell the difference."

Kurt Vonegut: Slaughterhouse Five

Delacorte Press, New York, U.S.A. 1966, Chapter 3, p. 60

\section{Introduction and motivation}

Expert managers (probably many other people) working in the maintenance of printing industry begin their day with the prayer cited above. Probably this is one - if not the only - common consistent characteristic of their professional life.

Revolutionary changes have occurred in the world's printing industry in the past three decades. The half

First received: 20.07.2010.

Accepted: 18.09.2010. millennium old "Gutenberg technology" is the history of printing industrial today. Electronics and computer technology have completely taken over the role of text generation. The integrated manufacturing systems, introduced to printing and bindery processing, have completed this development process. The changes have occurred in the Hungarian printing industry, with a couple of years delay though, with an enormous momentum. The conversion to market economy and the accession to the economical processes of the European Union have been and still are further strengthen- 
ing the position. The maintenance organization of the industrial branch is facing new, significantly different challenges deriving from the changes. Examples and scientific publications about the adaptation to the new situations are rare world-wide, and there are none in Hungary at all.

I feel fortunate because I could actively participate in the twisting momentum during the last 30 years at my field of interest. I've felt a great miss of the industrial adaptations of the theoretical and published maintenance or maintenance organization results ever since the beginning of my carrier. I quite early understood, as the scope of my scientific carrier became transparent, that I had to work on this unexplored area of science. I especially wanted to develop new solutions in the transfer of theoretical results to the practice. The more than 20 years old of my theoretical and research work - completed with the continuous practical work - in the field of maintenance organization of printing industry gives the background of this paper.

\section{Aim of the research, basic principals}

The aim of my research job is to explore new theoretical relationships in this field of science. A developed - currently missing - maintenance organization model, based on my practical and scientific results, would completely describe the specialties of this area's maintenance and would contain - especially the Hungarian - the features of the printing industry. It would consider the professional traditions and culture (their current level of development); nevertheless, it would integrate the required and acceptable modern methods of maintenance organization.

All these might be a significant professional support and motivational aid to the recipient medium - they are nursing really good relations with each other - to the maintainers of the printing industry, and might have an influential power to other employees working on different fields of printing industry management.

\section{Empirical investigation on the condition of printing industry maintenance}

The maintenance management model to be created according to my research method is based on the given answers to the challenges generated by changes.
Therefore, the current conditions, the understanding of current solutions and processes, the analysis of foreseen directions of developments were chosen as basis of construction. I carried out an assessment on the conditions of the Hungarian printing industry and its maintenance. On the one hand it was carried out by document-analysis; on the other hand I representatively surveyed the notable printing offices and maintenance enterprises. I also carried out a similar investigation in 1991-1992 (Horváth, 1993), so when I developed the latter method I aimed to get comparable results. Both investigations were carried out amongst the most important Hungarian printing offices because my maintenance model, whose formulation is the aim of this paper, is mainly defined for plants that independently organize their maintenance.

My former research assessment (in 1992) of the conditions was based on the answers of maintenance managers to 60 questions and answers of maintainers to 22 questions. I made the emphasis on these analyses in my current assessment. I decided to slightly modify the former surveys because they are still topical and contain answerable questions. The comparison has become more explicit. I found this advantage much more important in the comparative analysis than surveying new aspects.

In the first part of my investigation I surveyed the maintenance managers of those companies that are the subjects of my research. Altogether, 56 participants have replied, 32 of them also replied 12 years ago (48\% of the former replies and their proportion is $57 \%$ in the latter investigation). These are extremely beneficial values from the comparative point of view. I chose $10 \%$ inquiry proportion for the representativity of the latter survey amongst the maintenance experts of printing offices.

I determined the direction of changes and the professional profile of maintenance managers of the printing industry as a result of my survey.

I paid detailed attention to the role of increasing maintenance enterprises and their service capacity in the maintenance of printing offices during my investigation.

\section{Challenges and future trends}

I determined those factors - I call them "challenges" -, based on the results of my empirical investigations,

Table: Maintenance surveys at the printing plants in Hungary

\begin{tabular}{|l|c|c|c|}
\hline \multicolumn{2}{|c|}{ The range of the surveys } & $2003-2004$. & Identities \\
\hline Range & $1991-1992$. & 30 & 22 \\
\hline Number of investigated printing offices & 26 & $52 \%$ & $39 \%$ \\
\hline Their proportions in the overall Hungarian printing industry production & $60 \%$ & 67 people (87\%) & 57 people (81\%) \\
\hline Maintenance managers & 139 people (20\%) & 50 people (10\%) & 7 people \\
\hline Maintainers & & 32 people \\
\hline
\end{tabular}


Conditions and future challenges of maintenance in the printing industry (From the point of the printing plants)

\begin{tabular}{|c|c|}
\hline $\begin{array}{l}\text { PossiBILITIES } \\
\text { - Easily accessible and usable maintenance provider market of } \\
\text { the EU from the servicing and consultancy point of view } \\
\text { - Maintenance training of the future printing office managers } \\
\text { Training of maintenance manager experts to the demands of } \\
\text { printing industry } \\
\text { - Employment of external service providers } \\
\text { Adoption of known maintenance organization practices from } \\
\text { other industries. }\end{array}$ & $\begin{array}{l}\text { THREATS } \\
\text { - Old maintenance manager generation } \\
\text { - Not enough young executive maintenance specialists } \\
\text { - Not conscious enough application of maintenance strategies } \\
\text { - } \quad \text { Dorced cost reduction, outsourcing pressure } \\
\text { - }\end{array}$ \\
\hline $\begin{array}{l}\text { STRENGTHS } \\
\text { - Practiced and experienced maintenance managers } \\
\text { - Maintenance managers are members of the companies' } \\
\text { management } \\
\text { - Good communication between the maintenance managers in } \\
\text { the industry } \\
\text { Accessible and developing Hungarian maintenance service } \\
\text { providers }\end{array}$ & $\begin{array}{l}\text { WEAKNESSES } \\
\text { - Insufficient private maintenance infrastructure } \\
\text { - } \quad \text { Macagement based on experiences, too little empirical proofs } \\
\text { properties } \\
\text { - } \quad \text { Lpplication of low efficiency motivational and interest systems } \\
\text { management } \\
\text { - Low introductory level of maintenance information systems } \\
\text { - Importance of quality-centric mentality in maintenance } \\
\quad \text { Lack of modern management model }\end{array}$ \\
\hline
\end{tabular}

Figure 1: SWOT matrix describing the changes influencing the maintenance in the Hungarian printing industry

which have a great influence on the aspects and productivity of organization in the printing industry maintenance in the near future. The chosen - developed methods, equipments and strategies have to give and effective answer to these challenges.

I sufficiently explored those weaknesses and threats based on the results of my investigation - that appear in and affect the maintenance of printing offices. I summarized those strengths and possibilities, which could mean the pledge of development.

I summarized them in a SWOT matrix (Figure 1) for the sake of sufficient compactness and better transparency. Not only did I analyze the changes of external environment but also entered the plants. Taking the investigations into account the improvable maintenance organization model is determined by the challenges of weaknesses and threats. Methods, solutions, information and practices are supporting-pillars, which are based on printing industry experience and applying the knowledge of general maintenance science, giving the bases and up-to-date assistance to the effective operation of modern printing industry machines.

\section{Working hypothesis of the development of the maintenance model}

I listed those tools and skills, during the development of the elements of the maintenance model, which are needed to improve maintenance and might help the implementation of effective predictive maintenance management in the printing industry. These are also the elements of the maintenance model development.

One part of it is so called "hard" tool(s), hard skills in the Anglo-Saxon scientific literature. This consists of those experiences, professional content, skills that are required to perform a predictive, proactive maintenance. Such conceivable equipments are the technicaland time planning, operator management tasks, condition monitoring, fault analysis, corrective instructions and so on.

Soft skills are extremely important in maintenance as well. These skills are not connected to the profession itself, but to a successful performance. Such, so called, "inconceivable" characteristics are the attitude patterns and routines. Long term plans, short term goals, personal management, communication and cooperation, problem solving and taking responsibility, learning skills and abilities, teamwork, performance and evaluating ability.

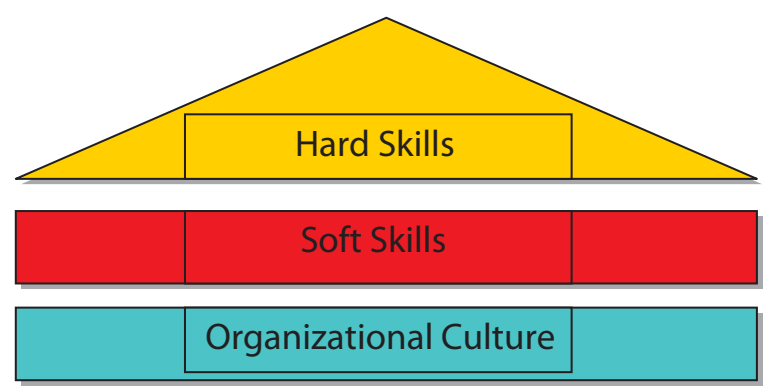

Figure 2: The pyramid of skills is built on the bases of organizational culture (Thomas, 2005)

The pyramid of "hard" skills is based on the bases of "soft" skills presented on Figure 2. However, the basis of these is the organizational culture actually. Based on this approach, I attached the analysis and construction of organizational culture to the development of maintenance model.

During the development of the integrated maintenance management model I took the aspects of Maintenance 


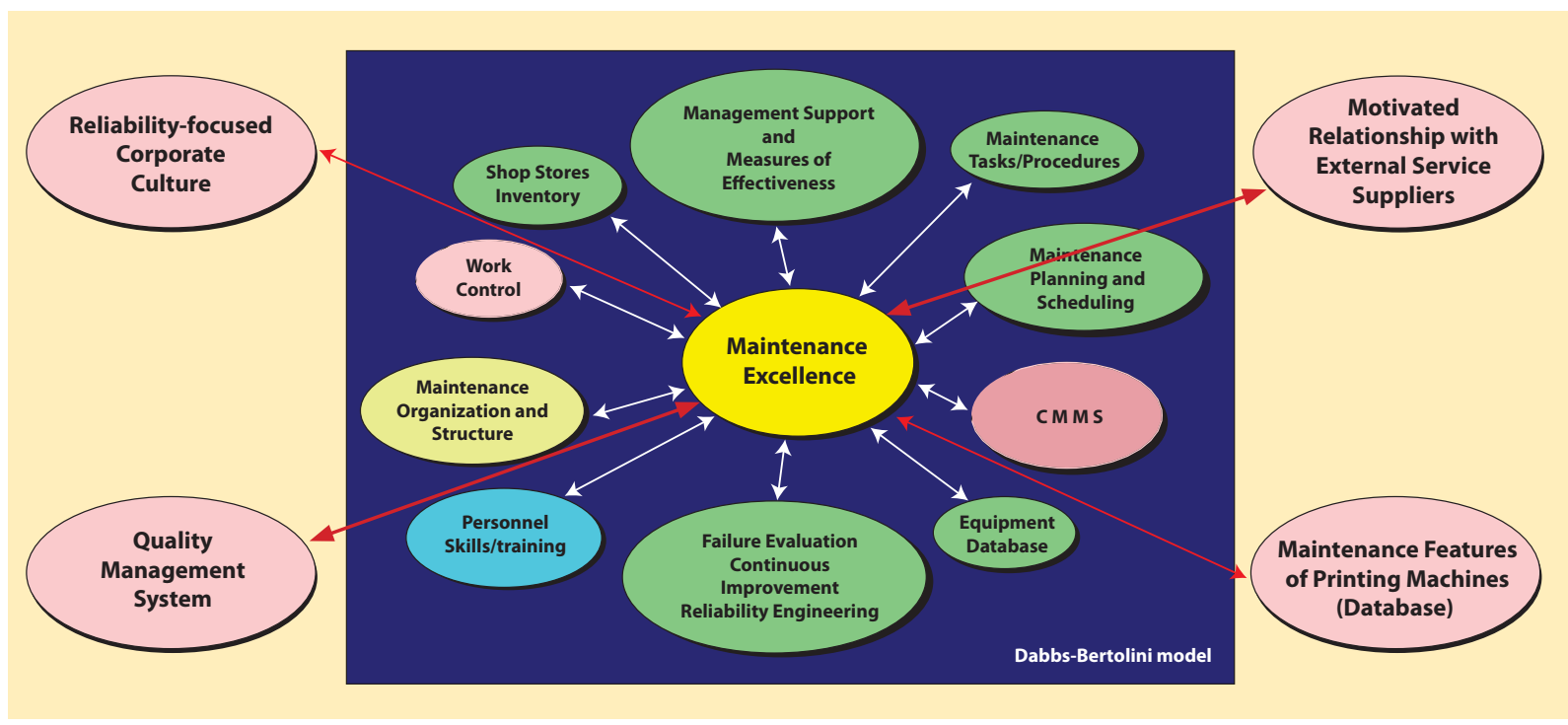

Figure 3: Improved Maintenance Excellence Model

Excellence, which became wide spread along with quality management systems, into account for the evaluation of CBP (Current Best Practices). I applied one of the most common used Dabbs and Bertolini 10 dimensional model (Dabbs, n.d.). This model will only meet the challenges of maintenance in the printing industry if it is completed with four new aspects. This completion is presented on the Figure 3. It is necessary to redefine the original four elements according to the printing industry needs.

\section{Knowledge management and quality commitment}

It is especially true for maintenance that professional knowledge is increasingly revaluating. I present examples, with the tools of knowledge management, about what does the professional preparedness really mean to maintenance employees. How is it possible to treat knowledge as "value" using the frame of quality systems and how to motivate colleagues to obtain it?

I developed and tested a score system, which can and is qualified to assess the preparedness of colleagues, evaluate their development and further motivate. This typically regards expertise verified by "paper", which is an inevitably important "tool" for working.

The annual personal evaluation, which should be incorporated into the quality management system of the enterprise, is intended to measure the "application" success of the learnt knowledge. This qualification is carried out collectively by the employee and the manager according to the following seven groups of aspects: professional preparedness, effective and fault-free activities, conformance with the quality regulations, initiative willingness, teamwork and cooperation.

I developed a survey, as a part of the knowledge management block of the quality management system, which "synchronizes" with colleagues related to professional self-evaluation and learning willingness.
Printing offices increasingly rely on services of external maintenance suppliers. They are mostly willing to cooperate with companies whose quality management system can be adjusted to the system of their clients. So, the effective performance of the accepted job is reguaranteed. I developed novel methods and solutions to motivate the activity of printing industry maintenance service providers with the help of common platforms in the quality management systems. Unambiguous and redundancy-free decision processes were established on identical working surfaces to accelerate the common actions. Uniform documentation system and application of controlled feedback promote the success of collective labor.

I analysed and classified the types of service providers' contracts, determining mutually advantageous approach and the critical points as well.

\section{Construction of reliability oriented culture}

Changes are always generated by economical factors, never ever "required" by the culture itself. In our case the necessity of changes in maintenance strategies is the most relevant driving force of changes in culture. A model that defines the concept of measurability is required to control the efficiency of changing steps. The model, published by Thomas (2005), postulate a relationship between the eight concepts used in changemanagement, the elements of changes, and the four fundamentals of organizational culture according to Figure 4.

Based on these concepts I developed a survey consisting of 32 questions, which tested the degree of progression in the construction of reliability-oriented maintenance culture. The test is based on the eight pillars of culture changes in accordance with the four elements of culture. The answers to $8 \mathrm{x} 4$ questions show positive 


\begin{tabular}{|l|c|c|c|c|}
\hline \multirow{2}{*}{ Eight Elements of Change } & \multicolumn{4}{|c|}{ Four Elements of Culture } \\
\cline { 2 - 5 } & Values & Role Models & Rites \& Rituals & Cultural Infrastructure \\
\hline Leadership & $\mathrm{M}$ & $\mathrm{M}$ & $\mathrm{M}$ & $\mathrm{m}$ \\
\hline Work Process & $\mathrm{M}$ & $\mathrm{M}$ & $\mathrm{M}$ & $\mathrm{m}$ \\
\hline Structure & $\mathrm{M}$ & $\mathrm{m}$ & $\mathrm{M}$ & $\mathrm{m}$ \\
\hline Group Learning & $\mathrm{M}$ & $\mathrm{M}$ & $\mathrm{m}$ \\
\hline Technology & $\mathrm{M}$ & $\mathrm{M}$ & $\mathrm{M}$ & $\mathrm{M}$ \\
\hline Communication & $\mathrm{M}$ & $\mathrm{M}$ & $\mathrm{M}$ \\
\hline Interrelationships & $\mathrm{M}$ & $\mathrm{M}$ & $\mathrm{m}$ \\
\hline Reward & $\mathrm{M}$ & $\mathrm{M}$ & $\mathrm{m}$ & $\mathrm{m}$ \\
\hline & \multicolumn{2}{|c|}{$\mathrm{M}-$ Majos Interaction } \\
\hline
\end{tabular}

Figure 4: Relationships between the organizational culture and the elements of changes (Thomas, 2005)

trends of satisfaction degrees. The assessment related to certain change elements is interpretable on a 20 point scale. The survey can be improved and altered based on this concept.

The interested system, based on the taken responsibility of technical conditions, is an effective motivational tool of the development in reliability oriented company culture. This system motivates the employees to execute the determined maintenance tasks in a proactive way.
I developed a method based on the system of maintenance instructions to increase the maintenance reliability.

\section{Modern methods of maintenance organization of printing offices}

One of the major conclusions of my investigation, which analysed the maintenance management in print-

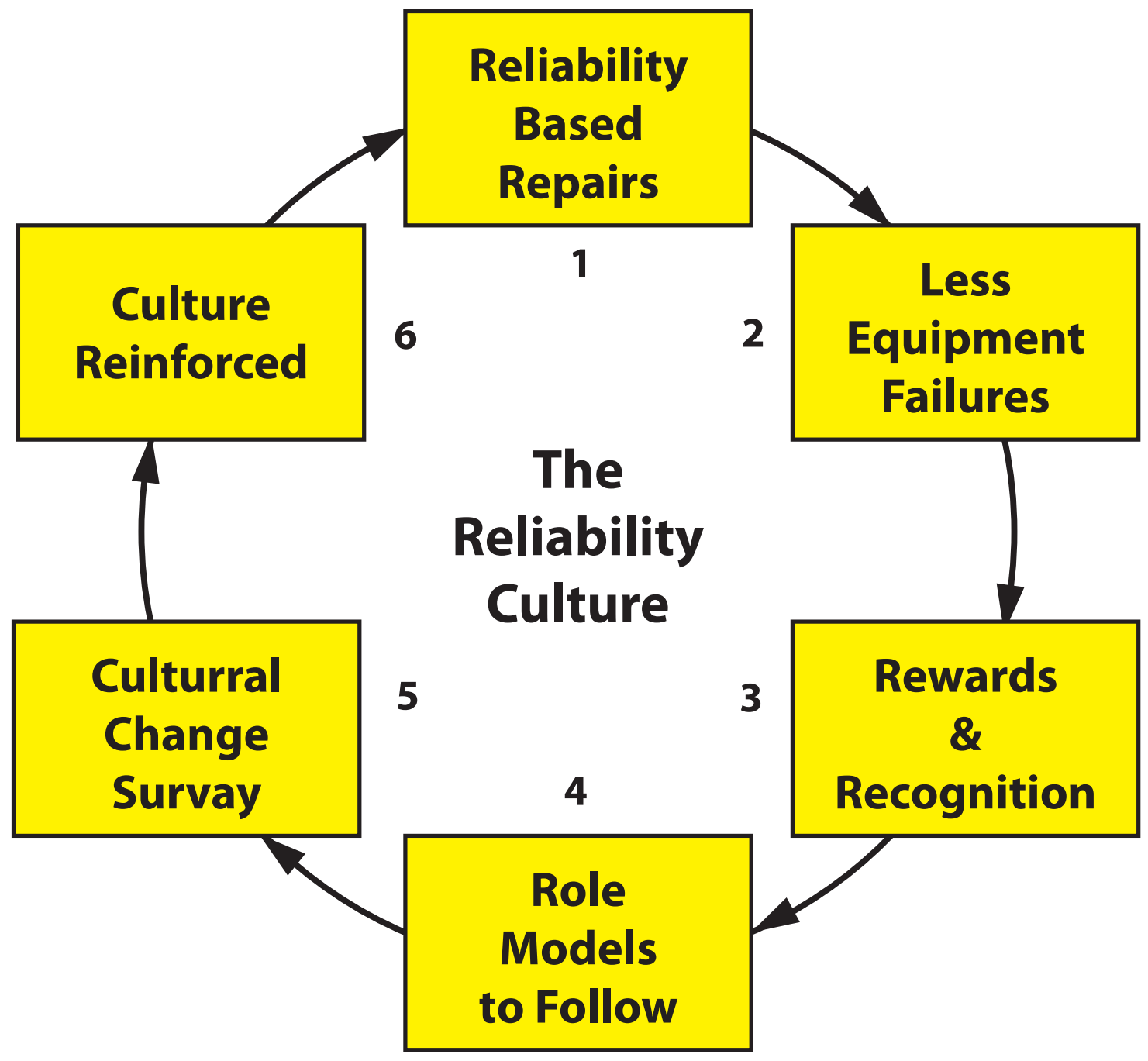

Figure 5: Model to develop a maintenance organization system of printing offices Developing of reliability culture module 
ing industry, was that the organizational solutions are mainly preventive. My efforts tend to strengthen the predictive and proactive concept in the tools and methods of organization adapted in my maintenance model (Horváth, 2009).

The types of maintenance tasks can be classified with planning and scheduling features. Therefore, I developed the classification of maintenance task categories (primer, secondary and tertiary line tasks).

The modern and adequately adapted informatics background significantly increases the efficiency of maintenance management. I developed the computer programs and data processing system of maintenance machine monitoring system and event log database especially for printing industry applications.

I analysed and integrated e-maintenance, the future challenge, into the model.

\section{Integrated maintenance management model of printing plants}

The maintenance management model, which is build up of the previously detailed elements, is the sum of those steps and instructions, which promote the organization of maintenance - in accordance with the current and future requirements - of a given printing plants on a higher level.

The maintenance management model is build up of two significant elements. One of them, construction of reliability culture module (Figure 5), ensures the framework for the continuous development and securing the achieved results.

This infiltrates into, following a modern approach, ev- ery organizational processes represented by the information and management relationship module.

This integrated model is mainly descriptive and can only be represented comprehensively. One of the most important aspects of the development was that the model could be introduced in details and step-by-step. The maintenance managers would face many conflicts if they decided to solve the maintenance of printing plants with such an approach. It is essential that the introduction of specific partial solutions should be a resulting answer and a positive motivation for the users. Therefore, I developed specific elements to be independently fit for life. Specific redundancies, repeated solutions cannot be avoided, but it hardly causes any additional expenditure during the application. The other element of the model is the information and management module. I summarized those information and management relationships, which form the frame of the maintenance improvement model (Figure 6).

This model is build up of 6 fundamental blocks. Member(s) of the operative maintenance management are in the centre (frontline). The external maintainers are treated as the internal maintenance personnel. All tasks of employment are carried out through the maintenance management with respect to every maintenance event; even it is a random corrective action or preventive task. Maintenance management is responsible for the operation of maintenance database. The aim is to integrate as much information as possible directly (online) or systematically to the database (machine monitoring system, event log, work sheet system).

Controlling and planning is based on the processing of data of maintenance database block and computerized information system.

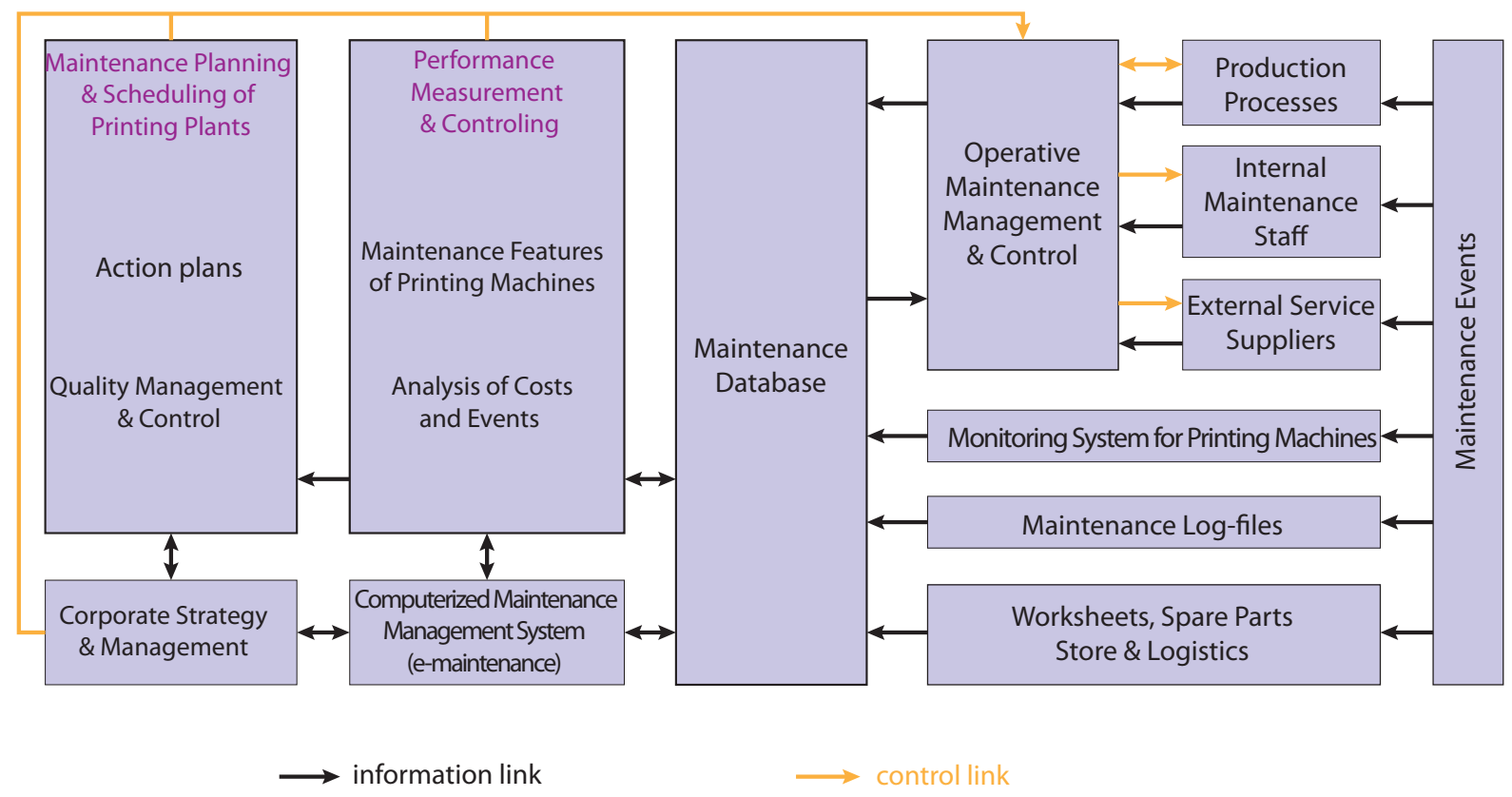

Figure 6: Model to develop the maintenance organization system of printing offices Information and management module 
Effective planning and checking the measurements are enabled by the maintenance controlling module with the knowledge of maintenance properties and the analysis of costs or events.

The planning block contains the maintenance tasks of quality management systems. The Computerized Maintenance Management System (CMMS) supports the planning and controlling of maintenance with its regular functions, besides the database operation. It is important to connect the already existing or machine integrated information to the system. We can have a larger confidence and bigger safety in information services. It is also an important task to develop a bilateral information connection with the existing company management system (not listed in the model).

The data and information obligation of external service providers is planned through the operative maintenance management in the model, but it would be also useful to develop and apply automatic production of data and service forms.

The validity range of the model is mainly related to printing offices, where the condition assessment was carried out. Namely, those printing offices, where the production value exceeds 500 million HUF (2 million $€$ ) and/or the typical printing machinery is considered to be modern, high-capacity production lines. The output range also contains those specialized printing offices, where small product range is produced with high-tech machines and few employees. The integrated model is obviously applicable to those printing offices which don't have own maintenance personnel. The internal maintenance is carried out by staff operating the machines. However, staff and specialist are always required for the maintenance organization and the operative management. Altogether, approximately 500 enterprises could apply successfully the maintenance organization methods represented by the model. The model can be really successful in an effective environment. It improves the well structured enterprises. Therefore, its validity range can only be interpreted above the $90 \%$ range of the available indicators.

\section{Conclusion}

The results of my research, the summarized improvement steps, don't revolutionize the performance of the printing industry, but help, from step to step, to improve it through the improvement of maintenance. I can be a bit proud with moderation because I think I could accomplish something from the admonition of the "the greatest Hungarian":

$$
\begin{gathered}
\text {,... step-by-step, } \\
\text { carrying a poppy-seed to poppy-seeds, } \\
\text { adding a drop to drops ...". }
\end{gathered}
$$

(Lóránd Eötvös quoted the words of István Széchenyi in his presidential opening speech in the Hungarian Academy of Sciences on 10. May 1889) (Anon. 1891)

\section{References}

1. Anon. (1891) MTA Természettudományi Közlöny. Vol. XXII, issue 262.

2. Dabbs, T., Bertolini, D. (n.d.) A Lumber Mill's Renaissance: Cultural Change for Success. [Online] Avaliable from: http://www.maintenanceresources. com/referencelibrary/ezine/lumbermill.html

3. Horváth Cs. (1993) Computer aided maintenance modelforprinting plants. PhDdissertation,University of Veszprém, Veszprém.

4. Horvath, Cs., Gaal, Z., Kerekes, K. (2009) Extended model for modern printing machines. In: IARIGAI. $6^{\text {th }}$ International Research Conference on Advances in Printing and media Technology, 13 - 16 September, Stockholm, Sweden. pp.129-136.

5. Thomas, S. T. (2005) Improving Maintenance Reliability Through Cultural Change. New York, Industrial Press. 